\title{
Association of Budd-Chiari syndrome, essential thrombocythaemia, and celiac disease
}

\author{
Agnieszka Bakula', Pawel Laguna², Joanna Cielecka-Kuszyk³ ${ }^{3}$ Andrzej Kosciesza4, \\ Michal Brzewski', Piotr Socha' \\ 'Department of Gastroenterology, Hepatology, Nutritional Disorders and Pediatrics, The Children's Memorial \\ Health Institute, Warsaw, Poland \\ ${ }^{2}$ Department of Paediatrics, Haematology, and Oncology, Medical University of Warsaw, Warsaw, Poland \\ ${ }^{3}$ Deptartment of Pathology, The Children's Memorial Health Institute, Warsaw, Poland \\ ${ }^{4}$ Deptartment of Radiology, The Children's Memorial Health Institute, Warsaw, Poland \\ ${ }^{5}$ Deptartment of Radiology, Medical University of Warsaw, Warsaw, Poland
}

\section{ABSTRACT}

Herein we report the case of a girl with association of Budd-Chiari syndrome (BCS), essential thrombocythaemia (ET), and celiac disease (CD). To our knowledge, this is one out of eight cases in the literature of BCS complicated with CD, and the only one complicated with ET. This case is particularly significant because anagrelide therapy was started at an unusually early age. A four-year-old girl with ET treated with anagrelide was admitted to our hospital with suspicion of BCS. Ultrasound colour Doppler and computed tomography imaging revealed enlargement of the caudate lobe, splenomegaly, accessory hepatic veins, umbilical vein recanalisation, and ascites. The diagnosis of the CD was confirmed by serology (EmA IgA $1: 800$, tTG IgA > $130 \mathrm{U} / \mathrm{ml}$ ). Two years later Duhring's disease was confirmed histologically with recovery after diet modification. Four years later she is still being treated with anagrelide, anticoagulant drugs and is on a well-controlled gluten-free diet.

KEY WORDS:

children, celiac disease, Budd-Chiari syndrome, essential thrombocythaemia.

\section{INTRODUCTION}

Herein we report the case of a four-year-old girl with Budd-Chiari syndrome (BCS) related to essential thrombocythaemia (ET), and celiac disease (CD). BCS is a very rare condition in children, and according to the literature, only a few cases have ever been reported that could indicate a link between BCS and CD in children. Because all the paediatric patients with this observed link came from North Africa and southern Europe, the appearance of the case in Poland indicates that factors other than environmental may play a role in its pathomechanism.

\section{CASE REPORT}

An 11-year-old girl reported in the $13^{\text {th }}$ month due to minor pain in the abdominal cavity. Laboratory tests revealed abnormal platelet count of $2085 \times 10^{3} / \mu \mathrm{l}(250-550)$ and hyperkalaemia $7.5 \mathrm{mmol} / \mathrm{l}(3.5-5.1)$. In the performed manual examination of the peripheral blood smear and bone marrow, no abnormalities were detected. In the search for the causes of hypercalcaemia, nephrological and endocrine disorders were excluded. Due to the increased number of platelets, ASA was administered.

In subsequent visits, the platelet count gradually increased to $2700 \times 10^{3} / \mu \mathrm{l}$. After obtaining the approval of

\section{ADDRESS FOR CORRESPONDENCE:}

Pawel Laguna, Department of Paediatrics, Haematology, and Oncology, Medical University of Warsaw, 63A Żwirki i Wigury St., 02-091 Warsaw, Poland, ORCID: 0000-0002-3656-5236,

e-mail: pawel.laguna@wum.edu.pl 
the Bioethics Committee, anagrelide was introduced at a dose of $0.25 \mathrm{mg}$ once a day and then $2 \times 0.25 \mathrm{mg}$, resulting in a decrease in the value of platelets to $300 \times 10^{3} / \mu$.

After starting ASA, the pain in the abdominal cavity disappeared.

A four-year-old girl with ET treated with anagrelide was admitted to the Department of Haematology with abdominal pain, vomiting, and dehydration. Physical examination indicated hepatosplenomegaly. Her physical growth was normal, with a body mass index of $16.7\left(50^{\text {th }}-85^{\text {th }}\right.$ percentile $)$. Laboratory tests revealed marked hypochromic anaemia with a haemoglobin level of $8.4 \mathrm{~g} / \mathrm{dl}$ (normal range 10.9-14.2), MCV $74.7 \mathrm{fL}$ (76$90)$, and thrombocytosis of $516 \times 10^{3}(140-400)$. Serum iron was $<10 \mu \mathrm{g} / \mathrm{dl}(20-145)$, and ferritin was $7.3 \mathrm{ng} / \mathrm{ml}$ (4.63-204). The alanine and aspartate aminotransferases were slightly elevated: ALT 55 U/1 (10-25), AST 137 U/1 (15-50). The serum albumin level was $2.7 \mathrm{~g} / \mathrm{dl}$ (3.5-5.2). Hyperammonaemia of $175 \mu \mathrm{g} / \mathrm{dl}(19-80)$ and coagulopathy INR 1.77 (0.9-1.25), and prothrombin index by Quick 70\% were found.

Ultrasound colour Doppler and computed tomography imaging revealed hepatosplenomegaly, ascites, normal portal vein, and obstructed hepatic veins with loss of flow and pleural effusion (Fig. 1).

Blood transfusions were given, and the patient was treated with diuretics and supplemental albumin. Reduction of anagrelide doses proved ineffective.

An ultrasound revealed enlargement of the caudate lobe, accessory hepatic veins, umbilical vein recanalisation, and obstruction of hepatic venous outflow.

After four days of initial diagnosis, the child was admitted to the Department of Gastroenterology, Hepatology, Nutritional Disorders and Pediatrics at the Children's Memorial Health Institute with suspicion of BCS.

A liver biopsy was performed after resolution of ascites, which showed sinusoidal dilatation and acinar con-

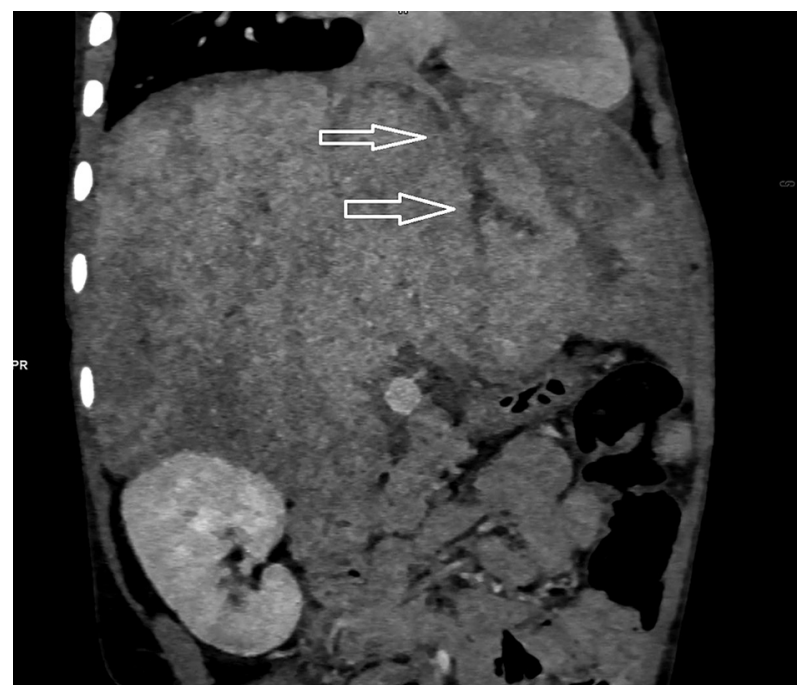

FIGURE 1. Computed tomography study revealed heterogenity of parenchyma of the liver. Hepatic veins were difficult to identify. Thrombus within the hepatic veins (arrows) gestion in zone 3 , and portal tracts without inflammation or ductular proliferation (Fig. 2). No features of vein occlusive disease or drug-induced liver toxicity were found. Hepatic intralobular granuloma formation was observed (Fig. 3). Gastroscopy showed three streaks of small oesophageal varices, hypertensive gastropathy, grooving, and scalloping of the duodenum. Histological examination of the duodenum revealed villous atrophy, crypt hypertrophy, and intraepithelial lymphocytes $>40 / 100 \mathrm{E}$, according to grade 3C of modified Marsh classification (Fig. 4). The diagnosis of the CD was confirmed by elevated titres of serum IgA antibodies against the endomysium of smooth muscles (EmA IgA) $1: 800$ and tissue transglutaminase (tTG IgA) $>130 \mathrm{U} / \mathrm{ml}$.

The girl received diuretics, albumin, anagrelide, and anticoagulant therapy with unfractionated heparin (UFH) followed by low-molecular-weight heparin (LMWH). Hepatic outflow was restored, and ascites and pleural effusion decreased. A gluten-free diet and ursodeoxycholic acid were also recommended. Eighteen months later pruritus was her main complaint. Her ascites was controlled. The serum concentration of albumin, ferrum, and activity of aminotransferases were normal. The level of bile acid was slightly elevated at $17.3 \mu \mathrm{mol} / \mathrm{l}$ (normal range $<10$ ). The titre of serum EmA IgA and level of $\mathrm{tTg}$ IgA were elevated to $1: 400$ and $130 \mathrm{U} / \mathrm{ml}$, respectively. Gastroscopy revealed small oesophageal varices with no progression of portal hypertension and duodenitis with features of active CD. Duhring's disease was confirmed histologically with recovery after diet modification. Six months after discharging the girl from the Department of Disease Control, after replacing warfarin with heparin at the INR 1.32 level, we diagnosed thrombophilia (protein C 55\% [70-140\%], protein S 50.6\% [60.1-113.6\%], factor $\mathrm{V}$ Leiden [positive] prothrombin gene mutation [G20210A] [negative] and antiphospholipid activity [APL] [negative]). We also found V617F mutation in the JAK2 gene in the girl's DNA.

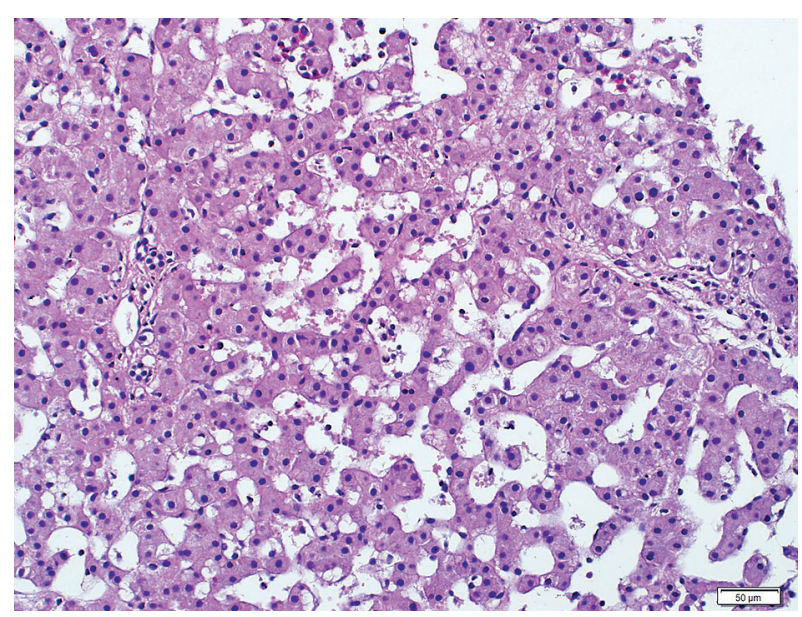

FIGURE 2. Liver biopsy specimen: H\&E, $200 \times$ hpf: sinusoidal dilatation, portal tracts without inflammation nor ductular proliferation 


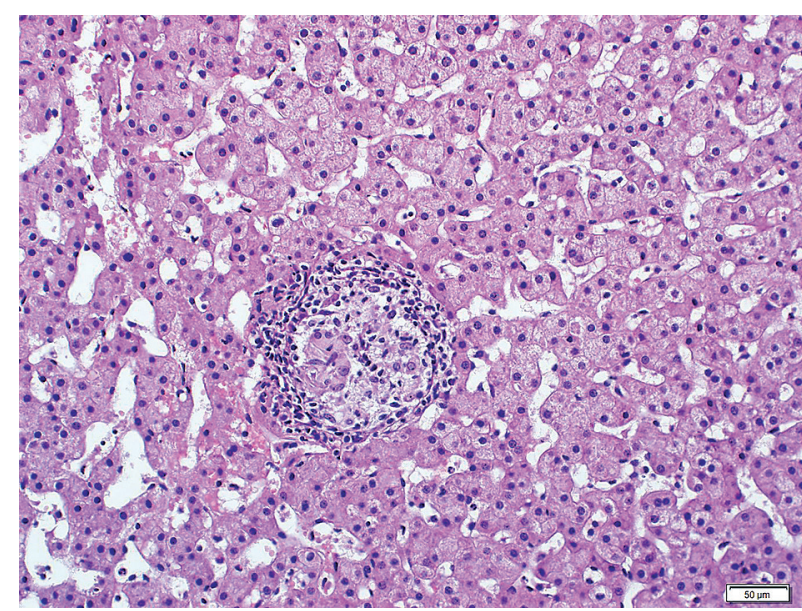

FIGURE 3. Liver biopsy specimen: H\&E, $200 \times$ hpf: intralobular granuloma formation in the absence of inflammatory infiltrates

Four years later she is still being treated with anagrelide, anticoagulant drugs and is on a well-controlled gluten-free diet.

The girl has a bone marrow puncture and trepanobiopsy performed every year - no signs of fibrosis or abnormal cells have been found. During a follow-up visit to the hospital in March 2020 results of control tests were as follows: $\mathrm{Hgb} 12.1(12.0-15.5) \times 10^{3} / \mu \mathrm{l}$, RBC 5.21 $(4.5-5.5) \times 10^{6} / \mu \mathrm{l}, \mathrm{WBC} 10.06(4.0-12.0) \times 10^{3} / \mu \mathrm{l}$, PLT $771(150-400) \times 10^{3} / \mu$ l, INR 2.42 . The patient has not reported abdominal pain, nausea, or vomiting related to treatment with anagrelide or warfarin.

\section{DISCUSSION}

BCS is defined as a venous outflow obstruction of the liver located from the small hepatic veins up to the junction of the inferior vena cava with the right atrium [1]. It is a rare disorder with typical presentation of hepatomegaly, abdominal pain, and ascites. BCS is less common in children. Only five per cent out of 177 cases of BCS described by Dilawari et al. were found to be below 12 years of age

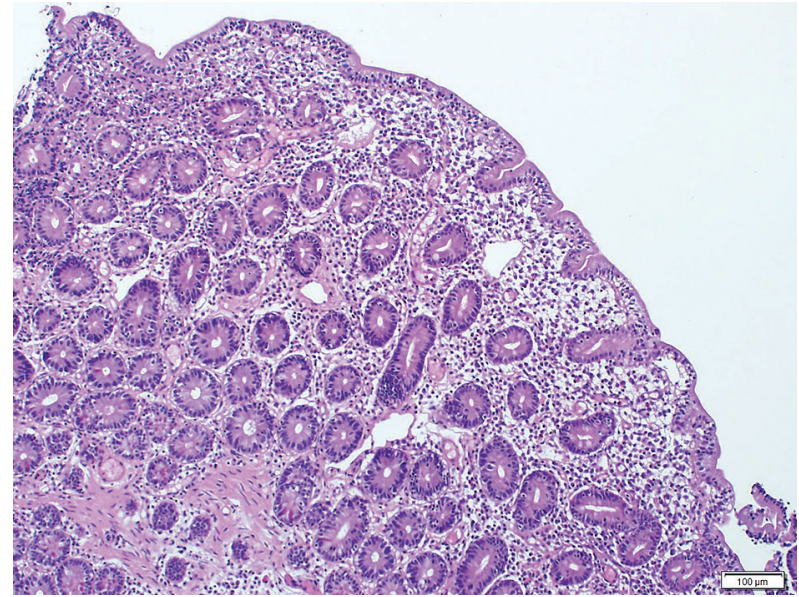

FIGURE 4. Mucosal biopsy of duodenum: H\&E, $200 \times$ hpf: villous atrophy, crypt hypertrophy, intraepithelial lymphocytes $>40 / 100 E$, according to grade $3 \mathrm{C}$ of modified Marsh classification

[2]. In most cases inherited or acquired thrombophilias were present [3]. Approximately 50\% of patients with BCS suffer from underlying myeloproliferative disorder [4]. Assessment of the V617F Janus tyrosine kinase 2 (JAK2) mutation should be performed.

In children the most common cause of BCS is a membranous obstruction of the inferior vena cava, but often the aetiology remains idiopathic.

$\mathrm{CD}$ is a frequent, lifelong enteropathy induced by wheat gluten in susceptible individuals. The most frequent presentation of liver dysfunction in CD is cryptogenic hypertransaminasaemia in $15-55 \%$ of untreated patients. In a few cases cryptogenic chronic hepatitis or liver cirrhosis requiring liver transplantation were observed. Interestingly, we observed hepatic granuloma in the liver biopsy. Similar changes have been described in association with celiac sprue and thrombocytopaenic purpura and were linked to autoimmune mechanisms $[5,6]$. Granuloma formation with periportal fibrosis was observed also in non-cirrhotic portal hypertension [7]. In the presented liver biopsy, we can also associate hepatic granuloma with CD, BCS, and ET. The association between CD

TABLE 1. An association of Budd-Chiari syndrome (BCS) and celiac disease (CD) in children - a review of the literature

\begin{tabular}{|l|c|c|c|c|c|}
\hline \multirow{2}{*}{ Author } & Age (years) & Nationality & $\begin{array}{c}\text { CD diagnosis (before } \\
\text { BCS/simultaneous) }\end{array}$ & Aetiology & Outcome \\
\hline $\begin{array}{l}\text { Boudhina et al., } \\
1990 \text { [1] }\end{array}$ & 10 & Tunisia & Before & - & Chronic liver disease \\
\cline { 2 - 6 } & 4 & Tunisia & Before & - & Death \\
\cline { 2 - 6 } & 2 & Tunisia & Before & Improved with diuretics \\
\hline $\begin{array}{l}\text { Hamdi et al., } \\
1990 \text { [10] }\end{array}$ & 1.7 & Tunisia & Simultaneous & Antithrombin III & Death \\
\hline $\begin{array}{l}\text { Marteau et al., } \\
1994 \text { [13] }\end{array}$ & 17 & Algeria & Before & Low protein C & $\begin{array}{c}\text { Improved } \\
\text { with diuretics }\end{array}$ \\
\hline $\begin{array}{l}\text { Manzano et al., } \\
2002 \text { [9] }\end{array}$ & 14 & Spain & Simultaneous & - & $\begin{array}{c}\text { Surgical shunts with good } \\
\text { results }\end{array}$ \\
\hline $\begin{array}{l}\text { Hmami et al., } \\
2011 \text { [12] }\end{array}$ & 7 & Morocco & Before & Death \\
\hline
\end{tabular}


and primary biliary cirrhosis with a prevalence of 3-7\%, autoimmune hepatitis (3-6\%), and primary sclerosing cholangitis (2-3\%) was proven [8].

Combination of $\mathrm{CD}$ and deep venous thrombosis is reported in the literature, but the association of BCS and CD is uncommon, especially in children. A review of literature revealed seven children [9-13] (Table 1) and 21 adults who suffered from this combined condition [14-24].

Most of the reported cases came from North Africa and southern Europe, as well as from Argentina and one from India. All paediatric patients came from this region.

That was the reason for the genetic and environmental factors in pathogenesis of the condition suggested by some authors [6]. Afredj et al., in a relatively large cohort of nine patients, did not identify specific pattern of HLA antigens for the association of CD with BCS [22]. The other hypothesis is the passage of toxic substances present in African food or a special diet into the portal circulation via an injured intestinal mucosa. Various prothrombotic mechanisms are suggested: deficiency of protein C, S, and antithrombin secondary to vitamin $\mathrm{K}$ malabsorption, folic acid deficiency and hyperhomocysteinaemia, thrombosis, and association with serum lupus anticoagulant. Nonetheless, in some cases the pathogenesis is unknown. Because underlying prothrombotic conditions were absent in more than $50 \%$ of the patients, Afredj concluded that CD played a role in the occurrence of thrombosis. In our patient both ET and CD were assessed as underlying causes of BCS.

Therapy in acute BCS is dictated by the liver biopsy, with hepatocyte necrosis indicating the need for placement of a decompressive shunt [25]. In our patient liver biopsy revealed no typical features of necrosis, and there was no indication for decompressive shunt or liver transplantation.

In the literature so far seven cases of BCS and CD in children have been described. All of them came from North Africa or southern Europe. Our patient is the third case ever described outside this region and the first paediatric patient outside this geographical zone. Aetiological investigation did not reveal the cause of BCS in five out of seven patients. One patient suffered from deficiency of antithrombin III, the latter had low concentration of protein C.

$\mathrm{CD}$ was diagnosed before BCS in five children. Portosystemic shunts were performed in one case, with good result. Conservative treatment proved effective in three out of seven patients. Three children died because of liver failure.

In our case the anticoagulant treatment was provided. In the context of secondary autoimmunity and increased risk of vasculitis in $\mathrm{CD}$, a well-controlled gluten-free diet is necessary. We suggest the use of serology to exclude CD in patients with BCS as a risk factor of thrombosis.

This case is particularly significant because anagrelide therapy was started at an unusually early age [26]. To our knowledge, this is one of eight cases in the literature of
BCS complicated with CD, and the only one complicated with ET. The appearance of the case in Poland may indicate that factors other than environmental may play a role in the pathomechanism of the diseases.

\section{DISCLOSURE}

The authors declare no conflict of interest.

\section{REFERENCES}

1. Janssen HL, Garcia-Pagan JC, Elias E, et al. Budd-Chiari syndrome: a review by an expert panel. J Hepatol 2003; 38: 364-371.

2. Dilawari JB, Bambrey P, Chawla Y, et al. The hepatic outflow obstruction (the Budd-Chiari syndrome). Medicine 1994; 73: 21-36.

3. Janssen HL, Meinardi JR, Vleggaar FP, et al. Factor V Leiden mutation, prothrombin gene mutation, and deficiencies in coagulation inhibitors associated with Budd-Chiari syndrome and portal vein thrombosis: results of a case-control study. Blood 2000; 96: 23642368.

4. Deltenre P, Denninger MH, Hillaire, $\mathrm{S}$ et al. Factor V Leiden related Budd-Chiari syndrome. Gut 2001; 48: 264-268.

5. Kahn O, Fiel MI, Janowitz HD. Celiac sprue, idiopathic thrombocytopenic purpura, and hepatic granulomatous disease. An autoimmune linkage? J Clin Gastroenterol 1996; 23: 214-216.

6. Vilaseca J, Guardia J, Cuxart A, et al. Granulomatous hepatitis: aetiological study of 107 cases. Nouv Presse Med 1978; 7: 33233325.

7. Strauss E, Valla D. Non-cirrhotic portal hypertension - concept, diagnosis and clinical management. Clin Res Hepatol Gastroenterol 2014; 38: 564-569.

8. Drastich P, Honsova E, Lodererova A, et al. Celiac disease markers in patients with liver diseases: A single center large scale screening study. World J Gastroenterol 2012; 18: 6255-6262.

9. Manzano ML, Garfia C, Manzanares J, et al. Coeliac disease and Budd-Chiari syndrome: an uncommon association. Gastroenterol Hepatol 2002; 25: 159-161.

10. Hamdi A, Ayachi R, Saad H, et al. Hemiplegie revelant un syndrome de Budd-Chiari associe a une maladie coeliaque chez un nourrisson. Presse Med 1990; 26: 1011-1012.

11. Boudhina T, Ghram N, Ben Becher S, et al. Syndrome de Budd-Chiari et atrophie villositaire totale chez l'enfant: a propos de 3 observations. Tunis Med 1990; 68: 59-62.

12. Hmami F, Chaouki S, Souilmi FZ, et al. Association of celiac disease and Budd-Chiari syndrome: a case report. Arch Pediatr 2011; 18: 95-102.

13. Marteau P, Cadranel JF, Messing B, et al. Association of hepatic vein obstruction and celiac disease in North African subjects. J Hepatol 1994; 20: 650-653.

14. Ben Chriz F, Habbassi H, Maamouri N, et al. Syndrome de Budd-Chiari associe a une maladie coeliaque. Rev Med Interne 2010; 31: 160-162.

15. Gelsi E, Ruitord F, Saint-Paul MC, et al. Budd-Chiari syndrome with a coeliac disease in patient native from North Africa. Gastroenterol Clin Biol 2004; 28: 903-905.

16. El Yuonsi S, Nassif T, Kuoch V, et al. Association de syndrome de Budd-Chiari et maladie coeliaque. Gastroenterol Clin Biol 2003; 27: 236-237.

17. Martinez F, Berenguer M, Prieto M, et al. Budd-Chiari syndrome caused by membranous obstruction of the inferior vena cava associated with coeliac disease. Dis Liver Dis 2004; 36: 157-162. 
18. Aguirrebarrena G, Pulcinelli S, Giovannoni AG, Gidekel L. Coeliac disease and Budd-Chiari syndrome: infrequent association. Rev Esp Enferm Dig 2001; 93: 611-612.

19. Kochhar R. Celiac disease and Budd-Chiari syndrome: report of a case with review of literature. Eur J Gastroenterol Hepatol 2009; 21: 1092-1094.

20. Danalioglu A, Poturoglu S, Gungor Gulluoglu M, et al. Budd-Chiari syndrome in a young patient with celiac sprue: A case report. Turk J Gastroenterol 2003; 14: 262-265.

21. Ouakaa-Kchaou A, Ennaifer R, Belhadj N, et al. Maladie coeliaque associee a un syndromede Budd-Chiari. Presse Med 2008; 37: 239-241.

22. Afredj N, Metatla S, Faraoun SA, et al. Association of BuddChiari syndrome and celiac disease. Gastroenterol Clin Biol 2010; 34: 621-624.

23. Karim A, Hliva W, Alaoui R. Association of Budd-Chiari syndrome and celiac disease A nw observation. Journal Africain d'Hepatogastroenterologie 2012; 6: 251-252.

24. Jadallah KA, Sarsak EW, Khazaleh YM, Barakat RM. Budd-Chiari syndrome associated with coeliac disease: case report and literature review. Gastroenterol Rep 2018; 6: 308-312.

25. Henderson JM, Warren WD, Millikan WJ Jr, et al. Surgical options, hematologic evaluation, and pathologic changes in Budd-Chiari syndrome. Am J Surg 1990; 159: 41-48.

26. Hankins J, Naidu P, Rieman M, et al. Trombocytosis in an infant with high trombopoietin concentrations. J Pediatr Hematol Oncol 2004; 26: 142-145. 